\title{
UPORABA GEOGRAFSKEGA INFORMACIJSKEGA SISTEMA PRI PREDLOGU NOVIH OBČIN SLOVENIJE
}

\author{
Danijel Boldin in Aleksander Jakoš
}

\begin{abstract}
Izvleček
$V$ prispevku je opisana uporaba GIS orodja pri pripravi predloga novih občin $v$ Sloveniji. Prikazana so izhodišča za pripravo grafične in atributne podatkoune baze, način priprave atributnih (šifriranje, izbiranje, združevanje podatkov popisa prebivalstua od 1961. do 1991. leta ipd.) in grafičnih podatkov (način oblikovanja novih mej občin, uporaba digitalnih podatkov mej sedanjih teritorialnih enot ipd.). Opisana je uporabljena računalniška oprema.
\end{abstract}

UDC $352.07: 91: 681.3$

Abstract

THE APPLICATION OF GIS FOR THE PROPOSAL OF NEW COMMUNES IN SLOVENIA

In this article the use of Geographic Information Systems (GIS) as a basis for the limitation of the new territorial units in Slovenia is described. Basic elements of arranging graphic and attributes data are described as well as the way of preparing different census data according to change of official commune codes and the way of digitalization of smaller territorial units, as a component part of new communes. Computer hardware and software is also presented.

\section{UVOD}

GIS-i so $\mathrm{v}$ zadnjih letih postali zelo uspešni pri informacijski podpori prostorskemu planiranju in drugim projektom, pri katerih so atributi vezani na podatke o prostoru. Ravno zmožnost teh orodij za uporabo prostorsko vezanih podatkov $\mathrm{z}$ njihovimi atributi nam omogoča njihovo prekrivanje, selekcijo, združevanje ipd. GIS-i dobro podpirajo prostorske baze podatkov in omogočajo oblikovanje različnih izpisov tako $v$ obliki tabelaričnih prikazov, kakor tudi barvnih izrisov različnih kart. Uporaba GIS-ov zahteva usklajeno delovanje različnih strokovnih sodelavcev, zmogljivo računalniško opremo ter dovolj zmogljivo GIS orodje.

V okviru priprav za oblikovanje celovite strategije prostorskega razvoja je Ministrstvo za varstvo okolja in urejanja prostora v začetku leta 1991

Danijel Boldin dipl. org. inf., Aleksander Jakoš dipl. geogr., Urbanistiěni inštitut Slovenije, Ljubljana, Jamova 18 
naročilo izdelavo raziskovalnega projekta: "Zasnova poselitvenega razvoja Slovenije", ki sta ga sofinancirala Ministrstvo za znanost in tehnologijo in Ministrstvo za varstvo okolja in urejanje prostora $v$ okviru inovacijskega sklada. Ta raziskava je predvidevala poleg demografskih elementov tudi proučitev teritorialno-upravne delitve kot instrumenta za usklajevanje prostorskih elementov.

Vse faze projekta so bile $v$ celoti izvedene na UI na naslednji strojni opremi: dva PC kompatibilna računalnika (80486 in 80386 s 110 MB trdima diskoma in barvnim ekranom), digitalnik AO format, peresni risalnik format $\mathrm{AO}$ in laserski tiskalnik.

Programska oprema, ki smo jo uporabljali pri tem projektu, je bila naslednja: PC ARC/INFO 3.4D za analizo atributnih in topoloških podatkov. Program za računalniško podprto načrtovanje AutoCAD 9.0, s katerim smo pripravili celoten proces zajemanja grafičnih podatkov (digitalizacije mej posameznih teritorialnih enot) in izrise večine končnih predlogov novih občin. S programskim sistemom za urejanje baz podatkov dBASE III+ in CLIPPER Summer $87 \mathrm{~s}$ katerima smo pripravljali in urejali atributno bazo podatkov in različne tabelarične prikaze. Za urejanje preglednic smo uporabljali program SYMPHONY 1.0, s katerim smo pripravili statistične in analitične izračune.

\section{PRIPRAVA PODATKOV}

Podatke o teritorialnih enotah smo razdelili na topološki (grafični) in atributni del. V začetku smo pripravljali ti dve bazi ločeno, vendar pa smo jih kasneje združili $v$ en sistem.

Grafični del je temeljil na karti merila 1:250.000 (Republiška geodetska uprava, 1991).

Atributni del smo pripravili na osnovi podatkov popisov od leta 1961 dalje oz. agregiranih baz podatkov po naseljih, krajevnih skupnostih in sedanjih občinah (podatki so bili prirejeni na šifrant naselij, ki je veljal za predhodne podatke popisa leta 1991, Zavod za statistiko Republike Slovenije).

Izhodišče za oblikovanje meja novih občin je bilo delovno gradivo dr. Igorja Vrišerja (Vrišer, 1991). V prvi fazi projekta, ko smo testirali možne pristope $\mathrm{k}$ izvedbi projekta smo pripravljali delovno topološko in atributno bazo (digitalizacija mej krajevnih skupnosti iz pregledne karte Slovenije v merilu 1:250.000) samo za nekatere dele Slovenije (območje notranjskih, primorskih, gorenjskih ipd. občin). Osnovna enota pri oblikovanju novih občin je bila krajevna skupnost. Nižje enote - naselja so nastopala samo $\mathrm{v}$ atributni bazi. V tej fazi smo določili strukturo topološke (podatkovni sloji) in atributne baze, osnovne grafične elemente, način povezovanja grafičnih elementov in šifriranja novih občin ter pripravili postopke za pove- 
zavo atributne in grafične baze. Pripravili smo nekatere testne tabelarične prikaze atributne baze, kakor tudi nekatere kartografske izrise.

\section{GIS STRUKTURA IN OBDELAVA PODATKOV}

Na osnovi delovnih rezultatov in pripravljenih delovnih postopkov smo se lotili oblikovanja novih občin. Predlog novih občin je bil oblikovan tako, da smo krajevne skupnosti (stanje 1991) združevali (združevanje segmentov KS $v$ nove poligone) $v$ nove občine. Pri tem posameznih krajevnih skupnosti nismo delili med več novih občin (kar pa za dokončen predlog seveda ne velja). Že pri digitalizaciji mej novih občin smo upoštevali topološke zahteve paketa za podporo geografskih informacijskih sistemov (način dodajanja, brisanja segmentov, povezava segmentov $v$ poligone ipd.) tako, da smo lahko $v$ nadaljevanju te podatke prenesli $v$ PC ARC/INFO. Nato smo pripravili način šifriranja novih občin. Pri tem smo uporabljali naslednja izhodišča:

- Oznaka nove občine je sestavljena iz 4 znakov. Prva dva znaka predstavljata oznako obstoječe občine, tretji in četrti znak pa oznako nove občine.

- Nove občine oštevilčimo zaporedno v okviru obstoječih občin.

- Oznake novih občin se pričnejo s številko 1.

- Oznako 1 dobi nova občina, ki ima enako ime kot obstoječa občina.

- Pri oštevilčenju novih občin se upošteva abecedni red imen občin.

Primer: 0301, 03 - oznaka obstoječe občine, 01 - oznaka nove občine. Na ta način smo ohranili povezavo med obstoječimi in novimi občinami.

Celoten proces grafične obdelave vhodnih podatkov - oblikovanja novih enot smo izvedli s programskim paketom AutoCAD. S pomočjo ARC/INFO-a pa smo izvedli postopke za topološko kontrolo in popravljanje topoloških napak grafične baze.

Po delovnem gradivu dr. Igorja Vrišerja smo pripravili dva variantna predloga nove upravne razdelitve Slovenije (Vrišer, 1991). Zaradi sistematičnosti in zaradi majhnega števila sprememb med obema predlogoma smo jih $v$ našem projektu poimenovali $z 2 a$ in $2 b$. Pri tem smo različne osnovne baze podatkov (prebivalci, delovna mesta ipd.) prilagodili na nove občine.

Medtem ko je bila osnova za grafično prikazovanje novih občin krajevna skupnost (po podatkih Geodetskega zavoda Slovenije) in le za leto 1991 (predhodni podatki popisa prebivalstva leta 1991) tudi izbrani podatki po teh krajevnih skupnostih, so bili vsi podatki o časovnih serijah pred letom 1991 obdelani na ravni naselij. Ker posamezna naselja sekajo meje krajevnih skupnosti, smo morali podatke prilagoditi. Pri tem smo praviloma krajevne skupnosti $v$ občinskih središčih združili v eno "naselje", v primeru večjih odstopanj pa smo si pomagali $z$ deleži prebivalstva po posameznih naseljih in krajevnih skupnostih (Pregled teritorialnih enot 1991 
in povezava šifranta naselji s KS, 1991). Časovne serije o številu prebivalcev so bile izdelane na ravni naselij in prilagojene na šifrant krajevnih skupnosti in šifrant naselij leta 1991. Poseben problem so predstavljala delovna mesta, saj se šifranta naselij (popis 1991) in šifrant delovnih mest (register avgust 1991) ne ujemata (razlike pri več kot 200 naseljih).

Pri atributnih podatkih smo morali najprej uskladiti šifrante naselij popisov prebivalstva leta 1961,1971 in 1981 na leto 1991 (za skupno število prebivalcev). Za podatke pred letom 1991 je bilo potrebno izdelati povezavo šifranta naselij s šifrantom krajevnih skupnosti. Nekatera naselja se namreč delijo $v$ več krajevnih skupnosti, zato je bilo potrebno v posameznih primerih deliti podatke po naseljih.

Atributna baza predloga novih občin je nastajala ob pripravi topološke baze. Atributne podatke smo pripravili na osnovi šifranta povezav med oznakami občin in oznakami krajevnih skupnosti. Za lažje oblikovanje šifrantov smo pripravili postopek v programu AutoCAD (AutoLISP), ki je omogočal zapis povezav teritorialnih enot na ASCII datoteko. Šifrant je vseboval naslednje podatke : oznaka nove občine, oznaka obstoječe občine, oznake pripadajočih KS.

Atributni podatki so bili vezani na obstoječe občine, nove občine in krajevne skupnosti. Nove občine smo opisali $z$ naslednjimi atributi:

- šifra nove občine,

- število prebivalcev leta 1961,

- število prebivalcev leta 1971,

- število prebivalcev leta 1981,

- število prebivalcev leta 1991,

- indeks gibanja števila prebivalcev v obdobju 1961-1971,

- indeks gibanja števila prebivalcev v obdobju 1971-1981,

- indeks gibanja števila prebivalcev v obdobju 1981-1991,

- indeks gibanja števila prebivalcev v obdobju 1961-1991,

- število prebivalcev, odsotnih zaradi dela v tujini leta 1991,

- število prebivalcev, odsotnih zaradi bivanja v tujini leta 1991,

- število stanovanj leta 1991,

- število gospodinjstev leta 1991,

- število kmečkih gospodarstev leta 1991,

- skupna površina,

- njivske površine,

- število zaposlenih,

- obdelovalne površine,

- kmetijske površine,

- oznaka demografske ogroženosti.

Atributni del pri krajevnih skupnostih je vseboval:

- šifra krajevne skupnosti,

- število prebivalcev leta 1991, 
Slika 1: Predlog novih občin Republike Slovenije.

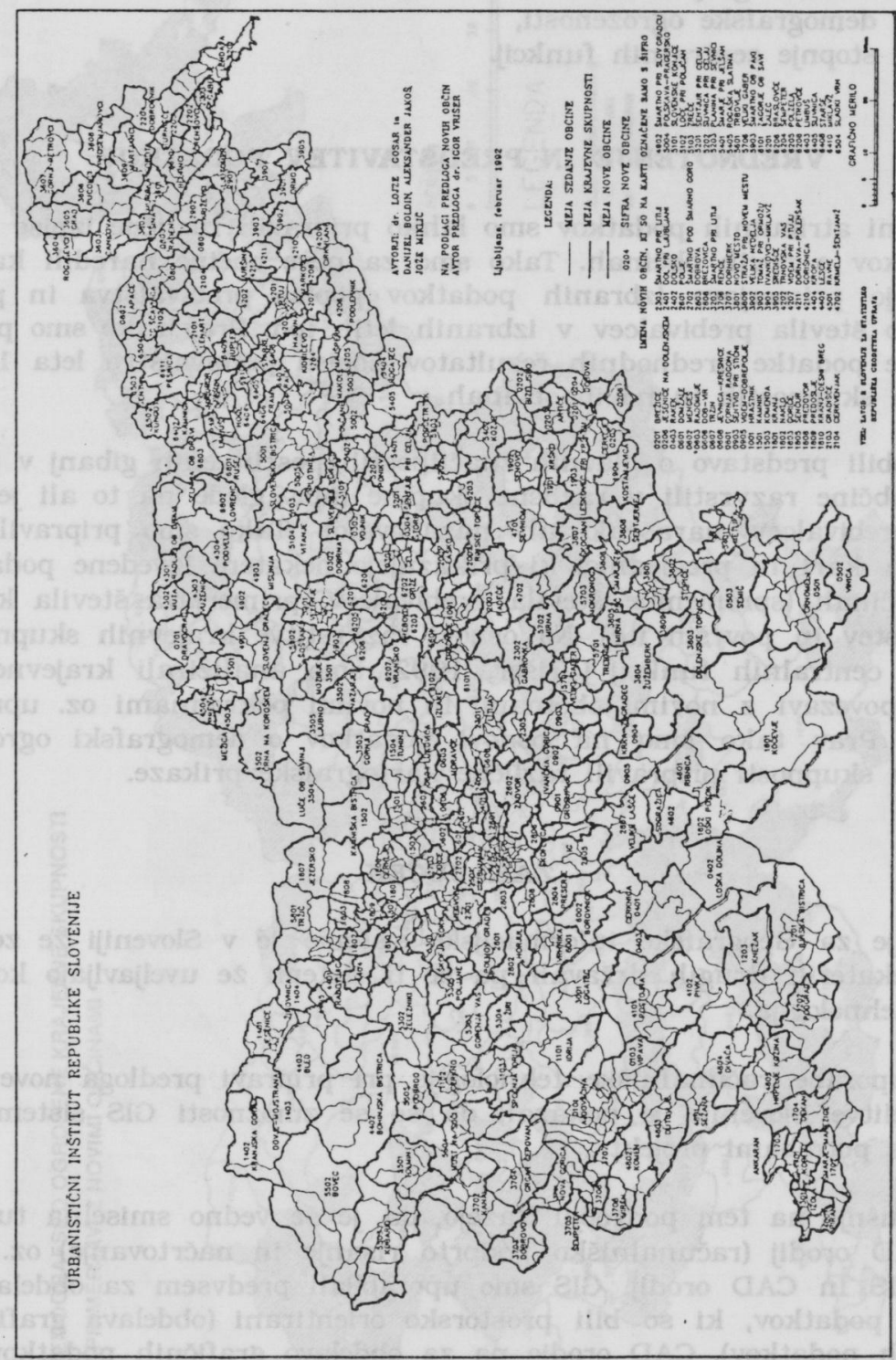


- število prebivalcev, odsotnih zaradi dela v tujini leta 1991,

- število prebivalcev, odsotnih zaradi bivanja v tujini leta 1991,

- število stanovanj leta 1991,

- število gospodinjstev leta 1991,

- število kmečkih gospodarstev leta 1991,

- oznaka demografske ogroženosti,

- oznaka stopnje centralnih funkcij.

\section{VREDNOTENJE IN PREDSTAVITEV PODATKOV}

Na osnovni atributnih podatkov smo lahko pripravili različne izpise in izrise podatkov o novih občinah. Tako smo za nove občine naredili karte, ki prikazujejo primerjavo izbranih podatkov popisa prebivalstva in površin, sprememb števila prebivalcev v izbranih letih ipd. Prav tako smo prikazali izbrane podatke predhodnih rezultatov popisa prebivalstva leta 1991 po krajevnih skupnostih in novih občinah.

Da bi dobili predstavo o glavnih značilnostih poselitvenih gibanj $v$ Sloveniji, smo občine razvrstili $v$ različne skupine (npr. glede na to ali je $v$ njih število prebivalcev naraščalo ali nazadovalo). Tako smo pripravili serijo tematskih kart in preglednic, ki prikazujejo nekatere izvedene podatke po novih občinah (spremembe števila prebivalcev, primerjava števila kmečkih gospodarstev in površin itd). Na osnovi razvrstitve krajevnih skupnosti po stopnjah centralnih funkcij (Vrišer, 1992) smo analizirali krajevne skupnosti $v$ povezavi $z$ novimi občinami in novimi pokrajinami oz. upravnimi enotami. Prav tako smo na osnovi podatkov o demografski ogroženosti krajevnih skupnosti pripravili različne kartografske prikaze.

\section{ZAKLJUČEK}

Zanimanje za Geografske informacijske sisteme je v Sloveniji že zelo veliko, v nekaterih drugih državah pa se ti sistemi že uveljavljajo kot standardna tehnologija.

Primer uporabe računalniške tehnologije pri pripravi predloga nove upravne razdelitve Slovenije je pokazal, da so se zmožnosti GIS sistemov zelo ujemale $\mathrm{s}$ potrebami projekta.

Naše izkušnje na tem področju kažejo, da je še vedno smiselna tudi uporaba CAD orodij (računalniško podprto risanje in načrtovanje) oz. kombinacija GIS in CAD orodij. GIS smo uporabljali predvsem za obdelavo velikih baz podatkov, ki so bili prostorsko orientirani (obdelava grafičnih in atributnih podatkov), CAD orodje pa za obdelavo grafičnih podatkov (orodje za risanje), na katere se lahko vežejo tudi atributi (ni pa nujno), vendar pa $v$ teh sistemih ni podpore za obdelavo atributnega dela podatkovne baze. 


\section{Slika 2.}

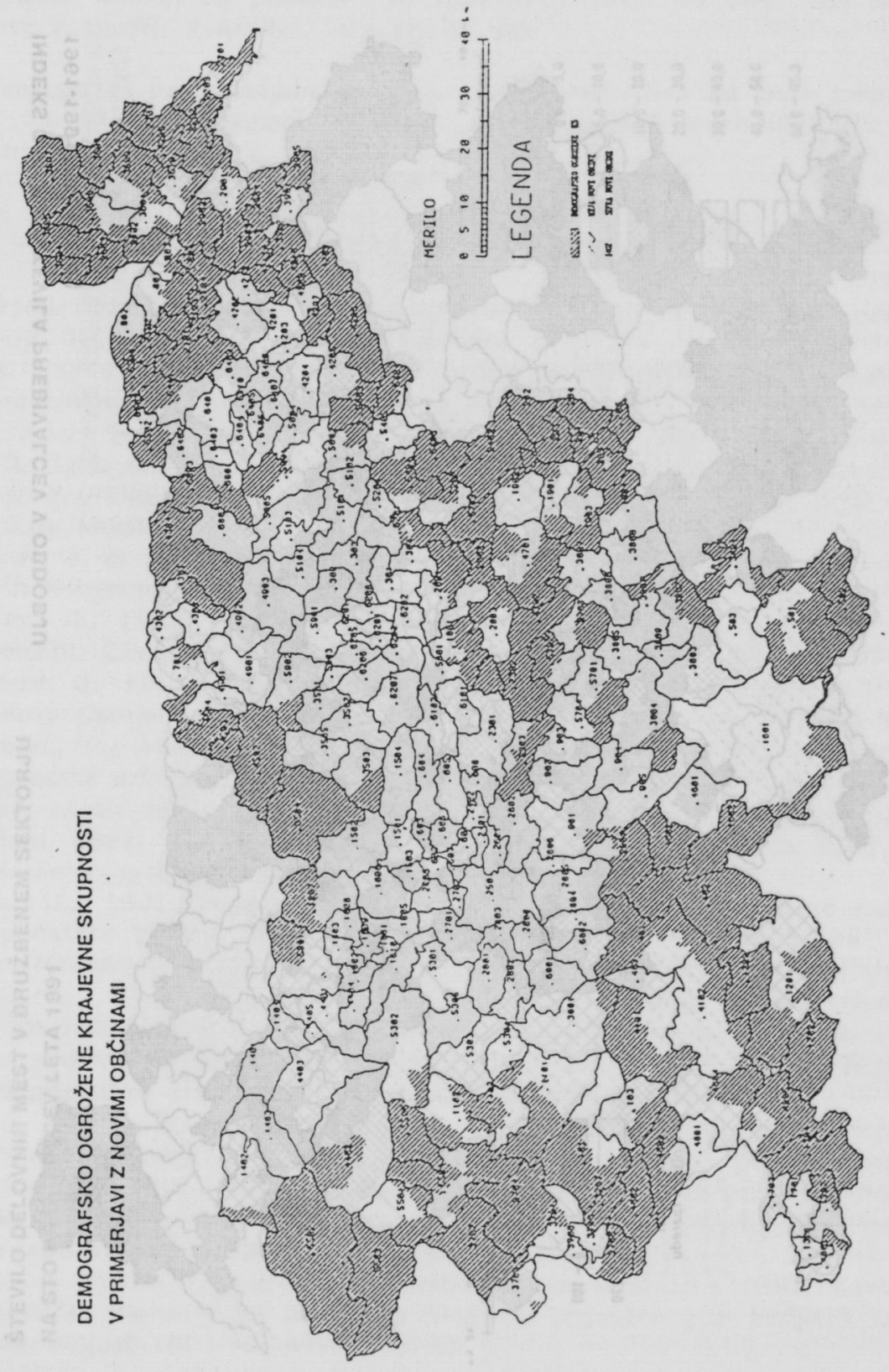


Slika 3.

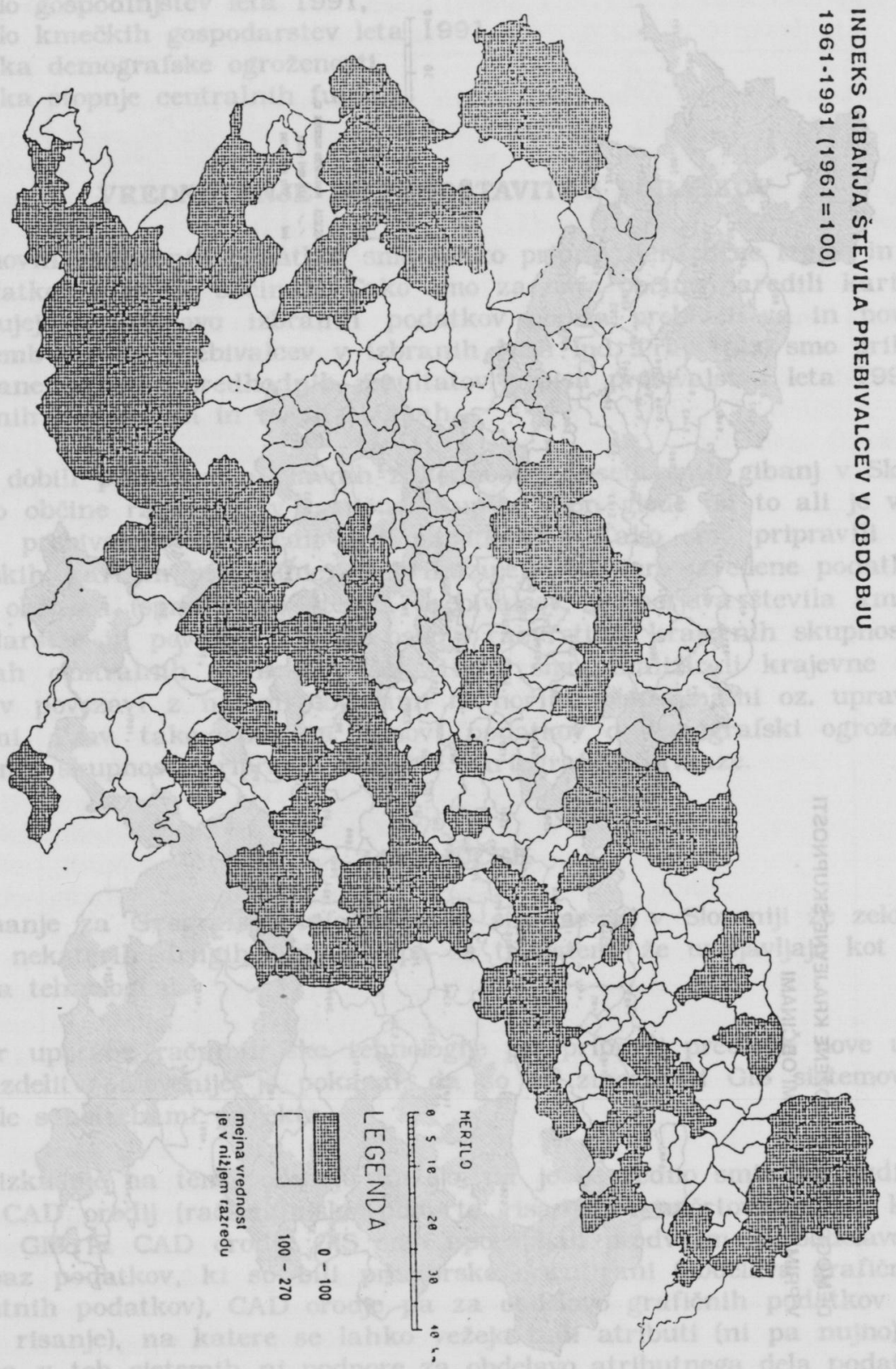


Slika 4.

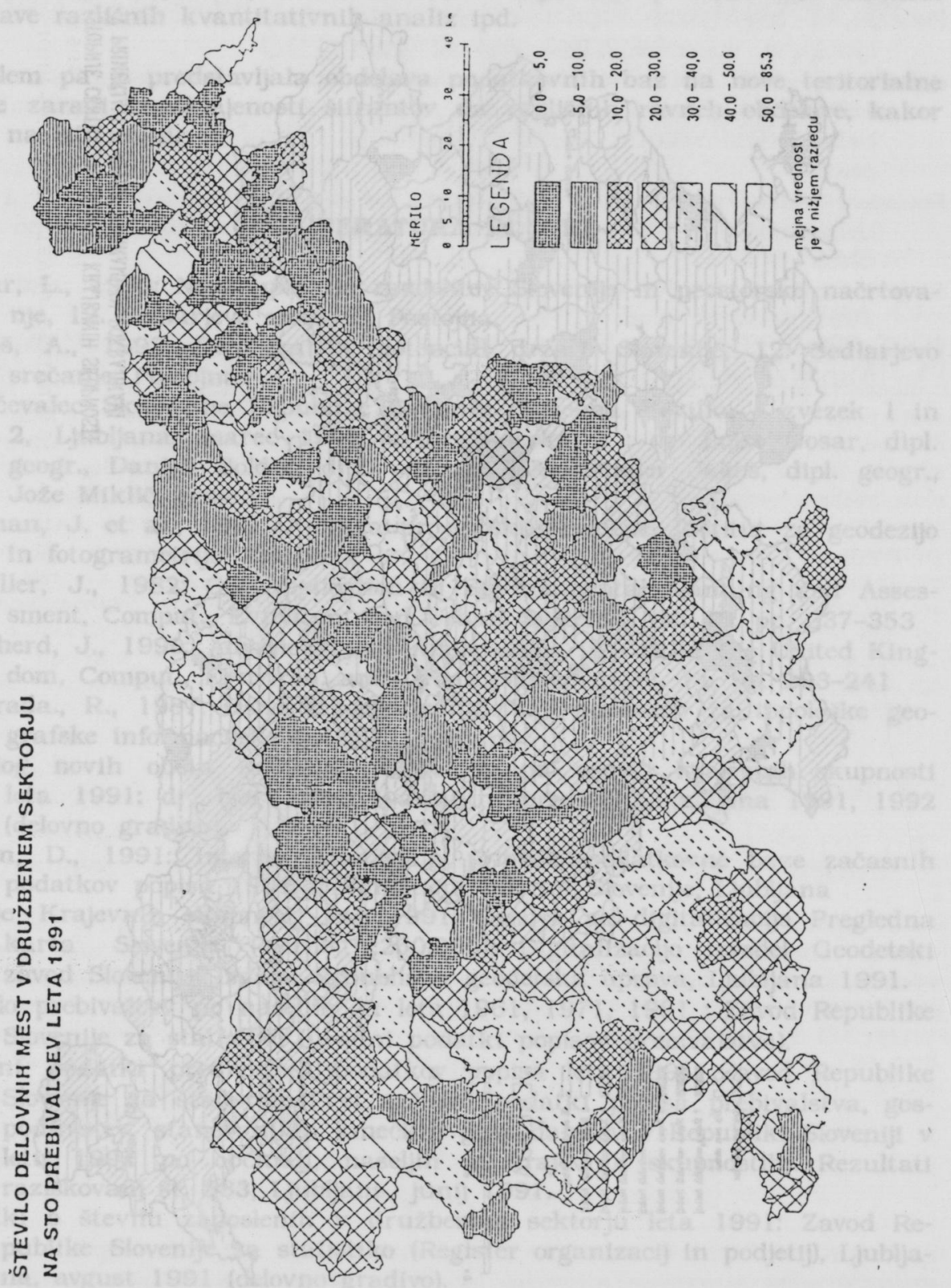




\section{Slika 5.}

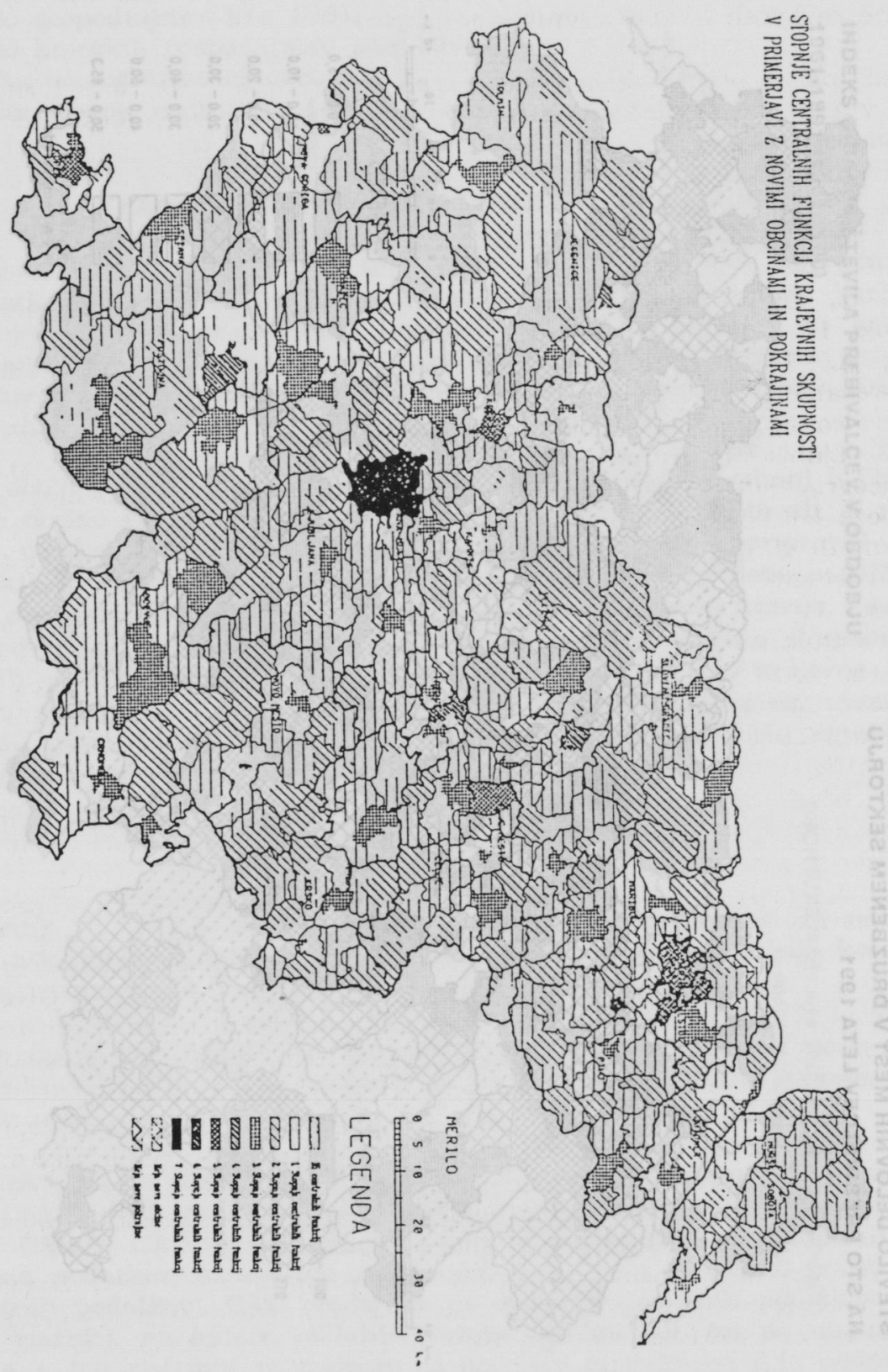


Pokazalo se je, da je bil največji prihranek časa pri pripravi različnih kartografskih izrisov zanesljivost podatkov, ki je večja kot pri klasičnih postopkih, dostop do podatkov in informacij, imeli pa smo tudi možnost izdelave različnih kvantitativnih analiz ipd.

Problem pa je predstavljala obdelava podatkovnih baz na nove teritorialne enote zaradi neusklajenosti šifrantov na različnih ravneh obdelave, kakor tudi na isti ravni.

\section{LITERATURA IN VIRI}

Gosar, L., 1992: Nova upravna razdelitev Slovenije in prostorsko načrtovanje, 12. Sedlarjevo srečanje, Postojna.

Jakoš, A., 1992: Demografski potencial države Slovenije, 12. Sedlarjevo srečanje, Postojna.

Poročevalec Skupščine Republike Slovenije, Posebna številka - zvezek 1 in 2, Ljubljana, marec 1992 (avtorji zvezka 2 : dr. Lojze Gosar, dipl. geogr., Danijel Boldin, dipl. org. inf., Aleksander Jakoš, dipl. geogr., Jože Miklič, geom.)

Rozman, J. et al., 1991: Analiza prostorskih evidenc, Inštitut za geodezijo in fotogrametrijo, Ljubljana

Schaller, J., 1982: Gis Application in Environmental Planning and Assessment, Comput., Evnviron. and Urban Systems, Vol. 16, pp. 337-353

Shepherd, J., 1990: Advanced and Applications in GIS in the United Kingdom, Comput., Evnviron. and Urban Systems, Vol. 14, pp. 223-241

Šmrada., R., 1987: Osnove korporiranih baz podatkov za topološke geografske informacijske sisteme, Ljubljana

Predlog novih občin Republike Slovenije, na osnovi krajevnih skupnosti leta 1991: dr. Igor Vrišer (variantni predlogi), Ljubljana 1991, 1992 (delovno gradivo).

Boldin, D., 1991: Interno poročilo o pripravi podatkovne baze začasnih podatkov popisa 1991: Urbanistični inštitut Slovenije, Ljubljana

Stanje Krajevnih skupnosti leta 1991: Osnova za digitalizacijo Pregledna karta Slovenije. (Merilo 1:250.000). Digitalizacijo izvedel Geodetski zavod Slovenije. Izdala: Republiška geodetska uprava, Ljubljana 1991.

Število prebivalcev po naseljih za leta 1961, 1971, 1981 : Zavod Republike Slovenije za statistiko (uradni podatki popisov prebivalstva).

Izbrani podatki predhodnih podatkov popisa leta 1991: Zavod Republike Slovenije za statistiko.(Prvi začasni podatki popisa prebivalstva, gospodinjstev, stanovanj in kmečkih gospodarstev v Republiki Sloveniji v letu 1991 po občinah, naseljih in krajevnih skupnostih). Rezultati raziskovanj št. 583, Ljubljana, junij 1991.

Podatki o številu zaposlenih v družbenem sektorju leta 1991: Zavod Republike Slovenije za statistiko (Register organizacij in podjetij), Ljubljana, avgust 1991 (delovno gradivo). 
Pregled teritorialnih enot v Republiki Sloveniji s šiframi, Zavod Republike Slovenije za statistiko, rezultati raziskovanj št. 541 , Ljubljana, julij 1991.

Podatki o površinah: Republiška geodetska uprava (Zemljiški kataster), Ljubljana, december 1986 (delovno gradivo).

Jakoš, A., 1991: Uskladitev šifranta naselij popisov prebivalstva leta 1961, 1971,1981 na leto 1991 (za skupno število stalnih prebivalcev): Urbanistični inštitut Republike Slovenije, Ljubljana 1991 (delovno gradivo).

Povezava šifranta naselij s šifrantom krajevnih skupnosti v letu 1991: Urbanistični inštitut Republike Slovenije, Ljubljana 1992 (delovno gradivo).

Stopnja centralnih funkcij krajevnih skupnosti, dr. Igor Vrišer, Ljubljana 1991, (delovno gradivo).

Demografsko ogrožene krajevne skupnosti: Uradni list Republike Slovenije 5/91-165, 6/91-262, 6/92-326. 